\title{
Silencing ferritin alleviates atherosclerosis in mice via regulating the expression levels of matrix metalloproteinases and interleukins
}

\author{
Mei Zheng ${ }^{1,2 \#, ~ L i z h u o ~ L i 3 \#, ~ Y u q i a n ~ L i u 44,5, ~ Y u n ~ L i a n g ~}{ }^{6}$ and Xiaoyong Qi1,7凶 \\ 'Department of Internal Medicine, Hebei Medical University, Shijiazhuang, China; 2Department of Cardiology, Shijiazhuang People's Hospital, \\ Shijiazhuang, China; ${ }^{3}$ Department of Cardiology, The First Hospital of Hebei Medical University, Shijiazhuang, China; ${ }^{4}$ School of Sport \& Exercise \\ Science, Lingnan Normal University, Zhanjiang, China; ${ }^{5}$ Research Institute of Exercise and Health, Lingnan Normal University, Zhanjiang, China; \\ ${ }^{6}$ Department of Clinical Laboratory, Shijiazhuang People's Hospital, Shijiazhuang, China; 7Department of Cardiology, Hebei General Hospital, \\ Shijiazhuang, China
}

This study was conducted to investigate the roles of ferritin in atherosclerosis. The mouse model of atherosclerosis was established by feeding ApoE knockout mice with a high-fat diet. The mice were then treated with ferritinoverexpressing and -silencing constructs, and assessed for interleukins (ILs) and matrix metalloproteinases (MMPs) levels using ELISA and Western blot analysis. After being fed with a high-fat diet, the ApoE knockout mice developed pro-atherogenic lipid profiles with elevated total cholesterol (TC), triglyceride (TG) and low-density lipoprotein cholesterol (LDL-C). They also showed increased atherosclerotic lesions including narrowed lumen diameter, reduced lumen area, and increased plaque size. Following injection of the overexpression and silencing constructs, mRNA levels of ferritin were increased and decreased, respectively, and at the same time the atherosclerotic lesions were aggravated and alleviated, respectively. Further analysis indicated that silencing of ferritin gene reduced IL-1 $\beta$ and IL-10 levels while overexpressing ferritin increased them. On other hand, the TNF-a levels showed an opposite trend. MMP8, MMP12 and MMP13 levels were increased or decreased significantly after the mice were injected with ferritin over-expression or silencing vectors, respectively. Western blot analysis showed that compared to the control, overexpressing ferritin resulted in increased expression of p-JNK while silencing ferritin decreased the expression. Meanwhile, the levels of pc-Jun remained unchanged. Our work demonstrates that ferritin can regulate the progress of atherosclerosis via regulating the expression levels of MMPs and interleukins. Silencing ferritin inhibits the development of atherosclerosis and is, therefore, worth being further investigated as a potential therapeutic approach for this disease.

Keywords: atherosclerosis, interleukin, ferritin, tumor necrosis factor, matrix metalloproteinases, inflammatory reaction

Received: 02 February, 2021; revised: 03 April, 2021; accepted: 07 April, 2021; available on-line: 03 November, 2021

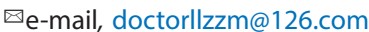

Acknowledgements of Financial Support: This study was funded by the Key Natural Science Project of Hebei Province, ZD2017048). \#Contributed equally to the work.

Abbreviations: IL, interleukin; MMPs, matrix metalloproteinases; TC, total cholesterol; TG, triglyceride; LDL-C, low-density lipoprotein cholesterol; $\mathrm{HDL}-\mathrm{C}$, high-density lipoprotein cholesterol; TNF- $a$, tumor necrosis factor- $\alpha$; TGF- $\beta$, transforming growth factor $\beta ; A p o E$ apolipoprotein E; PVDF, polyvinylidene difluoride; ELISA, enzymelinked immunosorbent assay; SDS-PAGE, polyacrylamide gel electrophoresis; SEM, standard error of the mean; ECM, extracellular matrix; MAPK, mitogen-activated protein kinase

\section{INTRODUCTION}

Cardiovascular and cerebrovascular diseases caused by atherosclerosis are common and leading causes of disability and death (Barquera et al., 2015). Atherosclerosis is a chronic inflammatory disease affecting large and medium arteries (Fatkhullina et al., 2016; Moss et al., 2018). A better understanding of cellular and molecular mechanisms underlying the pathogenesis of atherosclerosis is important for developing new prevention and treatment strategies as well as therapeutics for the disease. Studies have shown that inflammatory response plays an important role in the pathogenesis of atherosclerosis. For example, inflammatory cytokines such as tumor necrosis factor $\alpha(\mathrm{TNF}-\alpha)$, interleukin (IL)-1 $\beta$, IL-6 and lipid mediators could promote inflammatory reactions in atherosclerotic plaque (Auguet et al., 2016; Gostner \& Fuchs, 2016). The abnormally elevated expression of matrix metalloproteinases (MMPs) can lead to atherosclerotic plaque rupture, acute myocardial infarction and other cardiovascular events (Newby, 2016). On the other hand, other cytokines such as IL-10, transforming growth factor $\beta$ (TGF- $\beta$ ), and extracellular matrix (ECM) proteins can reduce atherosclerotic inflammation, leading to plaque regression (Hassan et al., 2018; Rahman et al., 2017).

Ferritin is an iron storage protein whose level reflects the iron reserve and iron load in the body (Golan et al., 2021). It is elevated during infectious diseases, tumors and inflammation (Jaksch-Bogensperger et al., 2020; Kim et al., 2013). Studies have shown that iron at high concentration could accelerate the formation of free radicals and oxidation of atherogenic lipoproteins such as cholesterol (Cozzi et al., 1990; Ikeda et al., 2006; Tuomainen et al., 2003). Therefore, increased ferritin and iron stores may be a risk factor for cardiovascular disease and have a causal role in the pathogenesis of atherosclerosis (Lauffer, 1991; MacDonald, 1993). Since proinflammatory and anti-inflammatory macrophages within arterial plaques have a different amount of intracellular iron (Kraml, 2017), it is still largely unclear how ferritin participates and regulates the atherosclerotic process, although iron level appeared to increase in the atherosclerotic plaques in deceased patients with coronary heart disease (Vlad et al., 1994). In addition, high ferritin was shown to predict poor prognosis in patients with coronary artery disease (Zhu et al., 2006).

To better understand the role of ferritin in pathogenesis of atherosclerosis, we examined the effect of ferritin 
(FTH1 gene) on atherosclerosis and related inflammatory reactions using the mouse model of atherosclerosis. The findings would provide new insights on the relationship between ferritin and atherosclerosis and clues for the treatment of atherosclerosis.

\section{MATERIALS AND METHODS}

\section{Animals}

Specific pathogen-free male apolipoprotein E-knockout $\left(\mathrm{ApoE}^{-/-}\right)$mice, aged 6 to 8 weeks, weighing 21.2 to $25.5 \mathrm{~g}$, were purchased from Tsinghua Animals, Beijing, China. All experimental protocols for the use of animals were approved by the Animal Care and Use Committee of Hebei Medical University. All animal experiments complied with the ARRIVE guidelines. Mice were housed under pathogen-free conditions, had access to standard mice feed and water ad libitum and were maintained at a 12/12 hour day/night cycle in climate-controlled conditions $\left(22 \pm 1^{\circ} \mathrm{C}, 40-70 \%\right.$ humidity). Animals were sacrificed by $\mathrm{CO}_{2}$ asphyxiation after completion of the experiments and tissues were collected. $\mathrm{CO}_{2}$ was supplied at a flow rate of $20 \%$ of the cage volume per minute $(5 \mathrm{~L} / \mathrm{min})$. The death after exposure to carbon dioxide was confirmed based on a careful assessment of the mice for cardiac arrest.

\section{Reagents and instruments}

Multi-shRNA vector pLKO.1-TRC was obtained from Addgene, USA; 293A cells were purchased from ThermoFisher Scientific, USA; automatic biochemical analyzer was purchased from Sigma-Aldrich, USA; blood lipid test reagents and ELISA kits were purchased from Wallysong Biotechnology, Wuhan, China; Trizol reagent (CW0580S) and Ultrapure RNA Extraction Kit (CW0581M) were products of CWbiotech, Beijing, China; cDNA Synthesis Kit (CW2141S) was obtained from Cwbiotech, Beijing, China; 2x SYBR Green PCR Master Mix (A4004M) was obtained from Lifeint, Beijing, China; mouse anti-human monoclonal antibodies against phospho-Ser63 c-Jun (pc-Jun) (1,50, ab195924) and phospho-Thr183/185 JNK (p-JNK) (1,50, ab131499) were obtained from Abcam, Cambridge, UK; HiScript II SuperMix for qPCR (R223-01) was from Vazyme, USA; PVDF membrane (IPVH00010) was a product of Millipore, USA; real-time fluorescent PCR system (CFX Connect) was obtained from Biorad, Shanghai; ultrasensitive luminescent solution (RJ239676) and pENTR Directional TOPO Cloning Kit were purchased from ThermoFisher Scientific, USA.

\section{Construction of silencing and overexpression vectors}

Using ThermoFisher's online RNAi Designer (https// www.thermofisher.com/us/en/home/life-science/rnai/ vector-based-rnai.html), short hairpin RNA sequences for ferritin (shRNA, 5'-AT'T'T'TGGCAACTGCCTCTG) were designed and inserted into pLKO.1-TRC. The lentivirus vector was amplified in $293 \mathrm{~A}$ cells, tittered according to the manufacturer's instructions and stored at $-80^{\circ} \mathrm{C}$ before use. To construct overexpression vector RNA was extracted from mice using Trizol RNA extraction kit and reversely transcribed into cDNA using cDNA synthesis kit according to the manufacturers' protocols. The cDNA was used as a template to amplify ferritin coding sequence using a pair of primers (forward 5'-CTGCAGATGCTTCTCAAGGCCTCCGC-
CGCTCTC, reverse 5'-GGTACCCTATGCCTGATGCAACTT'TCCT'TCATCCAGCAGCA). The amplified DNA fragment was recovered from the gel and cloned into pENTR ${ }^{\mathrm{TM}}$ Directional TOPO to generate pENTRferritin according to the manufacturer's instructions.

\section{Atherosclerosis model and treatments}

$\mathrm{ApoE}^{-/}$mice were fed a high-fat diet (containing $21.0 \%$ fat and $1.5 \%$ cholesterol, Research Diets, New Brunswick, NJ, USA) to generate an atherosclerosis model or regular diet $(10 \%$ fat and $0 \%$ cholesterol, Research Diets, USA) for use as a control. After 24 weeks, three mice were randomly selected from each group to examine blood lipid profiles to determine whether atherosclerosis modeling was successful. The model animals were then randomly divided into three groups $(n=10)$ to receive an intravenous injection of silencing construct $\left(10 \mu \mathrm{l}\right.$ at $\left.10^{8} \mathrm{UT} / \mathrm{mL}\right)$, overexpression construct $(5 \mu \mathrm{g}$ at $1 \mu \mathrm{g} / \mu \mathrm{L})$, or empty vector $(5 \mu \mathrm{g}$ at $1 \mu \mathrm{g} / \mu \mathrm{L})$ via tail vein as previously reported (Gorgens et al., 2019). After injection, the animals were reared at the same conditions as described above for 20 days and sacrificed for analysis.

\section{Blood lipid measurements}

Venous blood was collected from three randomly selected mice per group and analyzed for total cholesterol (TC), triglyceride (TG), high-density lipoprotein cholesterol (HDL-C) and low-density lipoprotein cholesterol (LDL-C) using COD-PAP and GPO-PAP methods according to the supplier's instructions.

\section{Hematoxylin and eosin (HE) staining}

$\mathrm{HE}$ staining was carried out to examine the plaque as described previously (Fischer et al., 2008). Briefly, the thoracic aortas were isolated and fixed in $4 \%$ paraformaldehyde, dehydrated in $70 \%, 80 \%, 90 \%$ and $100 \%$ alcohol and cleaned with xylene. Dehydrated tissue was embedded in paraffin, sectioned, dewaxed, and hydrated. The sections were stained with an aqueous hematoxylin solution for $3 \mathrm{~min}$, differentiated with hydrochloric acid for $15 \mathrm{~s}$, briefly washed, and counter-stained with eosin for $3 \mathrm{~min}$. After being washed in distilled water, dehydrated and cleared, the sections were sealed and examined under a microscope for aortic morphological changes.

\section{Real-time fluorescent quantitative PCR (qRT-PCR)}

Total RNA was isolated from blood 5 days after injection of constructs using the Trizol reagent according to the manufacturer's instructions and was reversely transcribed to cDNA for mRNA expression analysis using cDNA Synthesis kit according to the manufacturer's protocols. HiScript II qRT SuperMix for qPCR was used for quantification of $\mathrm{cDNA}$ according to the manufacturer's protocol using primers for ferritin (forward, GCCGAGAAACTGATGAAGCTGC, reverse, GCACACTCCATTGCATTCAGCC). Normalization was performed with GAPDH. The PCR was carried out in a total volume of $10 \mu \mathrm{l}$ containing $1.5 \mu \mathrm{l}$ of diluted and pre-amplified cDNA, $10 \mu \mathrm{l}$ of $2 \times$ SYBR Green PCR Master Mix and $1 \mu \mathrm{l}$ of each fluorescence probe. The cycling conditions were $50^{\circ} \mathrm{C}$ for $2 \mathrm{~min}, 95^{\circ} \mathrm{C}$ for $10 \mathrm{~min}$ followed by 45 cycles, each one consisting of $10 \mathrm{~s}$ at $95^{\circ} \mathrm{C}$ and $30 \mathrm{~s}$ at $58^{\circ} \mathrm{C}$. Samples were run in triplicate and the mean value was calculated for each treatment. The data were managed according to the previously described protocol (Livak \& Schmittgen, 2001). 
Table 1. Levels of serum lipids and atherosclerotic lesions parameters in mice after feeding with the high-fat diet (model) and the normal diet (ND) for 24 weeks.

\begin{tabular}{|c|c|c|c|c|}
\hline Lipids and atherosclerotic lesions & ND, mmol/L $(n=6)$ & Model, mmol/L $(n=6)$ & $\mathrm{t}$ & $P$ \\
\hline TG & $0.88 \pm 0.23$ & $4.89 \pm 0.63$ & 2.811 & 0.022 \\
\hline $\mathrm{TC}$ & $10.06 \pm 1.23$ & $25.06 \pm 2.23$ & 4.221 & 0.011 \\
\hline LDL-C & $8.06 \pm 1.11$ & $15.76 \pm 2.23$ & 2.183 & 0.031 \\
\hline HDL-C & $2.06 \pm 0.23$ & $2.09 \pm 0.33$ & 2.875 & 0.082 \\
\hline Minimal lumen diameter (mm) & $0.82 \pm 0.08$ & $0.55 \pm 0.03$ & 7.815 & 0.012 \\
\hline Lumen area $\left(\mathrm{mm}^{2}\right)$ & $0.44 \pm 0.02$ & $0.35 \pm 0.03$ & 6.215 & 0.017 \\
\hline Atherosclerotic plaque size $\left(\mathrm{mm}^{2}\right)$ & $0.04 \pm 0.01$ & $0.13 \pm 0.02$ & 5.236 & 0.011 \\
\hline
\end{tabular}

\section{Enzyme-linked immunosorbent assay (ELISA)}

Blood samples were collected from mice 20 days after injection. Serum concentrations of IL- $1 \beta$, TNF- $\alpha$, IL-10, MMP8, MMP12, and MMP13 were measured using ELISA kits according to the manufacturer's protocols. The absorbance (OD value) was read with a plate reader at a wavelength of $450 \mathrm{~nm}$ within $15 \mathrm{~min}$ after adding the stop solution.

\section{Western blot}

Thoracic aorta tissues were lysed with RIPA buffer containing protease inhibitors to extract proteins. Total protein was quantitated using BCA kit according to the manufacturer's instructions. After denaturation, $50 \mu \mathrm{g}$ of protein was separated using polyacrylamide gel electrophoresis (SDS-PAGE) and transferred to PVDF membranes. Non-specific binding was blocked by incubating in $5 \%$ non-fat milk in $1 \times$ Tris-buffered saline containing $0.1 \%$ Tween for 4 hours at room temperature and then the membranes were incubated with primary antibodies (mouse anti-human phospho-Thr183/185 JNK (p-JNK) (1.50) and mouse anti-human phospho-Ser63 c-Jun (pcJun) (1.50)) overnight. The blots were then incubated with goat anti- mouse horseradish peroxidase-conjugated secondary antibodies (12000) and the immunoreactive bands were visualized with a chemiluminescence kit. The gray values of bands were analyzed using Quantity One software.

\section{Statistical analysis}

All data were expressed as means \pm standard error of the mean (S.E.M.) obtained from at least three independent experiments. Statistical comparisons between groups were performed using one-way ANOVA followed by the Tukey post-hoc test. A value of $P<0.05$ was considered statistically significant.

\section{RESULTS}

High fat-diet generated pro-atherogenic lipid profiles and atherogenic lesions in $\mathrm{ApoE}^{-/-}$mice

After being fed with a high-fat diet for 24 weeks, the animals were tested for serum lipid levels. The results showed that compared to the mice fed with normal diet (ND), high-fat diet feeding resulted in significantly elevated levels of pro-atherogenic lipids in ApoE $/$ - mice. The levels of TG, TC, LDL-C and HDLC increased from $0.88,10.06,8.06$ and 2.06 to $4.89,25.06,15.76$ and $2.09 \mathrm{mmol} / \mathrm{L}$, respectively $(P<0.05$, Table 1$)$, while HDL-C remained unchanged $(P>0.05$, Table 1$)$. The size of atherosclerotic plaques was significantly greater in mice fed with the high-fat diet than fed with the normal diet. In addition, the vessel lumen was significantly narrowed $(P<0.05$, Table 1$)$.

\section{Ferritin silencing reduced atherosclerotic lesions}

The atherosclerotic model mice were then intervened with ferritin silencing and over-expression constructs and assessed for atherosclerosis-related changes. PCR assay showed that five days after injection of silencing and overexpression vectors, the serum ferritin mRNA levels were significantly down and up-regulated (Fig. 1), indicating that the vectors were effective in reducing and increasing ferritin expression, respectively. 20 days after the intervention, compared to mice treated with an empty vector, the area of atherosclerosis plaques was significantly increased in the mice treated with ferritin overexpression vector and significantly decreased in the mice treated with the silencing vector $(P<0.05$, Table 2$)$. The diameter and area of arterial lumen were significantly decreased in the mice treated with ferritin over-expression vector and significantly increased in the mice treated with ferritin silencing vector $(P<0.05$, Table 2$)$.

\section{Ferritin silencing changed IL-1 $\beta$, IL-10, and TNF- $\alpha$ levels}

We then measured IL-1 $\beta$, IL-10, and TNF- $\alpha$ levels in the mice 20 days after injection. Results showed that compared to mice treated with an empty vector the levels of IL-1 $\beta$ and IL-10 levels were significantly increased or decreased in the mice treated with ferritin over-expression or silencing vector $(P<0.05$, Table 3$)$, respectively. On the other hand, the levels of TNF- $\alpha$ levels were significantly decreased when the mice were treated with ferritin over-expression vector and significantly increased when the mice were treated with ferritin silencing vector $(P<0.05$, Table 3$)$.

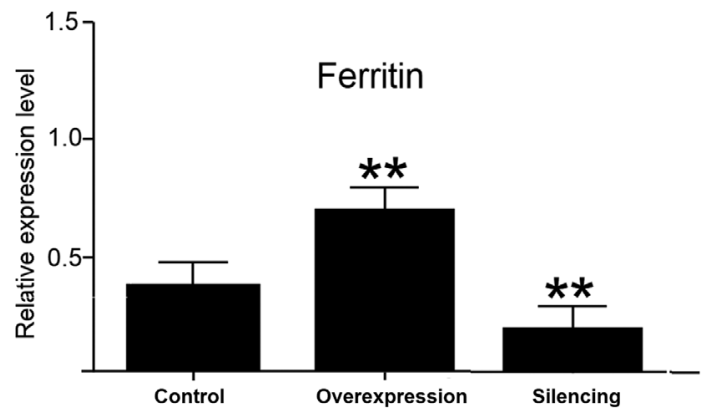

Figure 1. Serum ferritin mRNA levels following delivery of overexpression and silencing vectors in mice.

**denotes $P<0.01$ vs control. 
Table 2. Atherosclerotic plaque size and minimal lumen diameter and area $\mathbf{2 0}$ days after atherosclerotic mice were treated with ferritin silencing and overexpression constructs.

\begin{tabular}{|c|c|c|c|c|}
\hline Group & No. mice & Minimal lumen diameter (mm) & Lumen area $\left(\mathrm{mm}^{2}\right)$ & Atherosclerotic plaque size $\left(\mathrm{mm}^{2}\right)$ \\
\hline Control (empty vector) & 10 & $0.51 \pm 0.08$ & $0.29 \pm 0.05$ & $0.14 \pm 0.01$ \\
\hline Overexpression & 10 & $0.42 \pm 0.11^{\mathrm{a}}$ & $0.25 \pm 0.04^{a}$ & $0.28 \pm 0.02^{\mathrm{a}}$ \\
\hline Silencing & 10 & $0.55 \pm 0.03^{b}$ & $0.39 \pm 0.06^{b}$ & $0.08 \pm 0.01^{b}$ \\
\hline
\end{tabular}

aand bdenote $P<0.05$ vs control and overexpression vector, respectively.

Table 3. Levels of IL-1 $\beta$, IL-10 and TNF- $\alpha$ in mice 20 days after atherosclerotic mice were treated with ferritin silencing and overexpression constructs

\begin{tabular}{lllll}
\hline Group & No. mice & $\mathrm{IL}-1 \beta(\mathrm{pg} / \mathrm{mL})$ & $\mathrm{IL}-10(\mathrm{pg} / \mathrm{mL})$ & $\mathrm{TNF}-\mathrm{a}(\mathrm{pg} / \mathrm{mL})$ \\
\hline Control (empty vector) & 10 & $20.51 \pm 3.08$ & $10.04 \pm 1.11$ & $16.29 \pm 3.25$ \\
\hdashline Overexpression & 10 & $24.21 \pm 2.88^{\mathrm{a}}$ & $16.04 \pm 1.41^{\mathrm{a}}$ & $12.19 \pm 3.15^{\mathrm{a}}$ \\
\hline Silencing & 10 & $16.51 \pm 1.08^{\mathrm{b}}$ & $10.04 \pm 1.11^{\mathrm{b}}$ & $33.04 \pm 5.15^{\mathrm{b}}$ \\
\hline
\end{tabular}

a and ${ }^{b} P<0.05$ vs control and overexpression vector, respectively.

Table 4. Levels of MMP8, MMP12, and MMP13 in mice 20 days after atherosclerotic mice were treated with ferritin silencing and overexpression constructs.

\begin{tabular}{lcccc}
\hline Group & No. mice & MMP8 $(\mathrm{pg} / \mu \mathrm{L})$ & $\mathrm{MMP} 12(\mathrm{pg} / \mu \mathrm{L})$ & $\mathrm{MMP} 13(\mathrm{pg} / \mu \mathrm{L})$ \\
\hline Control (empty vector) & 10 & $20.21 \pm 1.08$ & $26.69 \pm 1.12$ & $20.04 \pm 1.11$ \\
\hdashline Overexpression & 10 & $23.61 \pm 1.38^{\mathrm{a}}$ & $29.33 \pm 1.12^{\mathrm{a}}$ & $26.14 \pm 1.71^{\mathrm{a}}$ \\
\hline Silencing & 10 & $18.21 \pm 1.01^{\mathrm{b}}$ & $22.49 \pm 1.02^{\mathrm{b}}$ & $16.04 \pm 0.91^{\mathrm{b}}$ \\
\hline
\end{tabular}

a and ${ }^{\mathrm{b}}$ denote $P<0.05$ vs control and overexpression vector, respectively.

Ferritin silencing changed the expression of MMP8, MMP12, and MMP13

In addition, MMP8, MMP12, and MMP13 levels were measured and results showed that they were increased significantly following treatment with ferritin over-expression vector and significantly decreased after treatment with ferritin silencing vector $(P<0.05$, Table 4).

\section{Ferritin silencing activated $\mathrm{p}-\mathrm{JNK} / \mathrm{c}-J u n$ signaling pathways}

The expression of proteins in the p-JNK / c-Jun signaling pathways was assessed and results are shown in Figure 2. Compared to the control ferritin over-expression resulted in increased expression of $\mathrm{p}-\mathrm{JNK}$, while ferritin silencing decreased the expression of the protein $(P<0.05$, Fig. 2A). On the other hand, the levels of pcJun remained unchanged ( $P>0.05$, Fig. $2 B$ ).

\section{DISCUSSION}

Ferritin is an important storage protein for iron supply and its role in atherosclerosis has not been fully elucidated at the molecular level, although clinical studies showed that patients with carotid atherosclerosis displayed elevated serum ferritin levels (Ma et al., 2015; Xu et al., 2017) and a population-based study in northeast Germany showed that there is a relationship between serum ferritin level and carotid atherosclerosis that was potentiated by LDL cholesterol (Wolff et al., 2004). The present study found that silencing FTH1 gene expression could alleviate the development of atherosclerotic lesions in atherosclerotic mice. FTH1 gene codes ferritin which is a major intracellular iron storage protein in prokaryotes and eukaryotes (Muhoberac \& Vidal, 2019). Silenc- ing this gene also reduced the levels of inflammatory cytokines and MMPs and down-regulated p-JNK signaling pathways. On the other hand, overexpressing the gene promoted the development of atherosclerotic lesions, increased the levels of inflammatory cytokines and MMPs, and up-regulated p-JNK signaling pathways. Since overexpression of ferritin would result in increased body iron
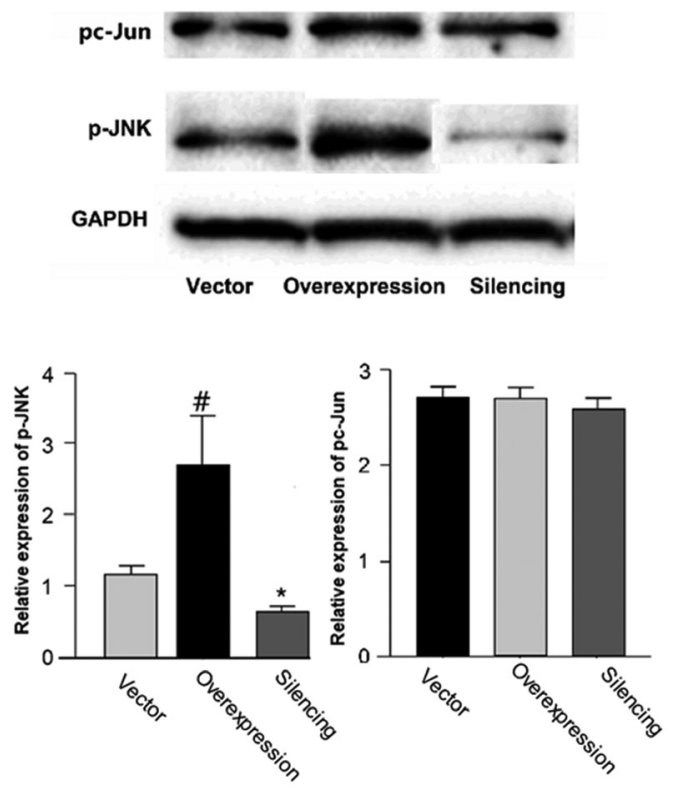

Figure 2. Expression of p-JNK and pc-Jun following overexpression and silencing of ferritin gene in mice.

Upper panel: representative Western Blots, lower panel: relative protein levels. * and "denote $P<0.05$ vs control. 
load, this may lead to enhanced progression of atherosclerosis as previously reported (Araujo et al., 1995; Lee et al., 1999). Furthermore, previous studies showed that the expression of the ferritin gene is up-regulated in atherosclerotic vessels (Pang et al., 1996), which is consistent with our observations that over-expression of ferritin has atherogenic activity, leading to increased plaque size and reduced aorta lumen diameter.

Inflammatory response plays an important role in the development of atherosclerosis which is regarded as a form of chronic vascular inflammation lesions (Soeki \& Sata, 2016; Taleb, 2016). Measurements showed that the levels of inflammatory cytokines such as IL-1 $\beta$ and IL-10 were significantly increased following treatment with ferritin overexpression construct, and significantly reduced once ferritin silencing construct was used, suggesting that ferritin may regulate atherosclerosis progression via inflammatory pathways. These findings are consistent with the previous observation that the secretion of serum ferritin is regulated by inflammatory hormones (Tran et al., 1997). For instance, it was found that IL-1 $\beta$ may increase the expression of both the heavy $(\mathrm{H})$ and light (L) ferritin subunit (Rogers et al., 1994) and ferritin could stimulate secretion of IL-10 and TNF- $\alpha$ in mice (Wang et al., 2017). Since ferritin level is statistically correlated with the levels of inflammatory biomarkers such as TNF- $\alpha$, IL-10, and high-sensitivity $C$ reactive protein (hs-CRP) and mortality of patients with the peripheral arterial disease (PAD), including atherosclerosis (Depalma et al., 2010), it is likely that ferritin has pro-atherogenic activity and further study is needed to investigate the mechanisms underlying ferritin-induced elevation of inflammatory hormones.

In atherosclerotic lesions, monocyte chemotaxis is induced to transform monocytes into macrophages. An important component of the inflammatory response is the secretion of MMPs to promote plaque rupture and to produce inflammatory cytokines such as TNF- $\alpha$, IL$1 \beta$ as well as lipid mediators to promote the inflammation in the plaque (Moore et al., 2013; Ruytinx et al., 2018). On the other hand, some reparative macrophages, such as alternatively activated M2 macrophages, could phagocytize dead cells or damaged tissue and release IL-10, TGF- $\beta$ and ECM proteins to resolve inflammation and stabilize or even reverse atherosclerosis (Barrett, 2020). Our study showed that ferritin increases the levels of IL-1 $\beta$ and IL-10 as well as the levels of MMPs, suggesting that ferritin may influence the polarization of macrophages, leading to an increased inflammatory response. Previously, it was found that iron overload could result in M2-like polarization of macrophages (Kao et al., 2020) and expression of the heavy subunit of ferritin is a key factor determining the macrophage polarization in isolated bone marrow-derived mouse monocytes (Bolisetty et al., 2015).

Our study showed that silencing of ferritin down-regulates the expression of MMP8, MMP12, and MMP13. MMPs and their endogenous tissue inhibitors (TIMPs) play complex dual role during late-stage progression and rupture of atherosclerotic plaques. MMPs can degrade the fibrous cap of the lesion, resulting in the rupture of the lesion, subsequent thrombus formation (Zhang et al., 2017), and acute myocardial infarction (Hong-Brown et al., 2015). Therefore, selective MMP inhibition would help limit cardiovascular morbidity and mortality.

$\mathrm{p}-J \mathrm{NK} / \mathrm{c}$-Jun signaling pathway is a major signaling cassette of the mitogen-activated protein kinase (MAPK) signaling pathway. It is involved in a number of cellular processes, including proliferation, embryonic devel- opment and apoptosis. Our data showed that JNK was down-regulated when the expression of ferritin was suppressed, suggesting that ferritin may regulate the progression of atherosclerosis via the $\mathrm{p}-\mathrm{JNK} / \mathrm{c}-\mathrm{Jun}$ signaling pathway. Early works also showed that when berberine was used to suppress atherosclerosis (Wan et al., 2018) or the chemerin gene was knocked down to alleviate atherosclerotic lesion (Liu et al., 2019), p-JNK expression was down-regulated, suggesting that $\mathrm{p}-\mathrm{JNK}$ expression is associated with atherosclerosis.

\section{CONCLUSION}

By overexpressing and silencing the ferritin gene, our work demonstrated that ferritin regulates atherogenesis in $\mathrm{ApoE}^{-/-}$mice. Silencing ferritin alleviated atherosclerotic lesions, reduced the levels of inflammatory cytokines and MMPs and deactivated the p-JNK/c-Jun signaling pathway, while ferritin overexpression resulted in opposite outcomes. Further study is needed to investigate the mechanism underlying the ferritin-mediated regulation of atherosclerosis.

\section{DECLARATIONS}

\section{Ethics approval and consent to participate}

This study was approved by the Animal Care and Use Committee of Hebei Medical University, Hebei, China.

\section{Consent for publication}

Not applicable.

\section{Availability of data and material}

The datasets used during the current study are available from the corresponding author upon reasonable request.

\section{Competing interests}

The authors declare that they have no competing interests.

\section{Authors' contributions}

MZ, LL and XQ designed the study. MZ, LL, YL and YL conducted the experiments, collected the data and performed analysis. YL, YL and XQ drafted the manuscript. All authors read and approved the final version of the manuscript.

\section{REFERENCES}

Araujo JA, Romano EL, Brito BE, Parthe V, Romano M, Bracho M, Montano RF, Cardier J (1995) Iron overload augments the development of atherosclerotic lesions in rabbits. Arterioscler Thromb V asc Biol 15: 1172-1180. https://doi.org/10.1161/01.atv.15.8.1172

Auguet T, Aragones G, Guiu-Jurado E, Berlanga A, Curriu M, Martinez S, Alibalic A, Aguilar C, Camara ML, Hernandez E, Ruyra X, Martin-Paredero V, Richart C (2016) Adipo/cytokines in atherosclerotic secretomes: increased visfatin levels in unstable carotid plaque. BMC Cardiovasc Disord 16: 149. https://doi.org/10.1186/s12872-0160320-5

Barquera S, Pedroza-Tobias A, Medina C, Hernandez-Barrera L, Bibbins-Domingo K, Lozano R, Moran AE (2015) Global overview of the epidemiology of atherosclerotic cardiovascular disease. Arch Med Res 46: 328-338. https://doi.org/10.1016/j.arcmed.2015.06.006

Barrett TJ (2020) Macrophages in atherosclerosis regression. Arterioscler Thromb Vasc Biol 40: 20-33. https://doi.org/10.1161/ATVBAHA. 119.312802 
Bolisetty S, Zarjou A, Hull TD, Traylor AM, Perianayagam A, Joseph R, Kamal AI, Arosio P, Soares MP, Jeney V, Balla J, George JF, Agarwal A (2015) Macrophage and epithelial cell H-ferritin expression regulates renal inflammation. Kidney Int 88: 95-108. https://doi. org/10.1038/ki.2015.102

Cozzi A, Santambrogio P, Levi S, Arosio P (1990) Iron detoxifying activity of ferritin. Effects of $\mathrm{H}$ and $\mathrm{L}$ human apoferritins on lipid peroxidation in vitro. FEBS Lett 277: 119-122. https://doi. org/10.1016/0014-5793(90)80823-2

Depalma RG, Hayes VW, Chow BK, Shamayeva G, May PE, Zacharski LR (2010) Ferritin levels, inflammatory biomarkers, and mortality in peripheral arterial disease: a substudy of the Iron (Fe) and Atherosclerosis Study (FeAST) Trial. J Vasc Surg 51: 1498-1503. https://doi.org/10.1016/j.jvs.2009.12.068

Fatkhullina AR, Peshkova IO, Koltsova EK (2016) The role of cytokines in the development of atherosclerosis. Biochemistry (Mosc) 81: 1358-1370. https://doi.org/10.1134/S0006297916110134

Golan MP, Pilsyk S, Muszewska A, Wawrzyniak A (2021) Ferritins in Chordata: Potential evolutionary trajectory marked by discrete selective pressures: History and reclassification of ferritins in chordates and geological events' influence on their evolution and radiation. Bioessays 43: e2000207. https://doi.org/10.1002/bies.202000207

Gorgens SW, Jahn-Hofmann K, Bangari D, Cummings S, Metz-Weidmann C, Schwahn U, Wohlfart P, Schafer M, Bielohuby M (2019) A siRNA mediated hepatic dpp4 knockdown affects lipid, but not glucose metabolism in diabetic mice. PLoS One 14: e0225835. https://doi.org/10.1371/journal.pone.0225835

Gostner JM, Fuchs D (2016) Biomarkers for the role of macrophages in the development and progression of atherosclerosis. Atherosclerosis 255: 117-118. https://doi.org/10.1016/j.atherosclerosis.2016.10.046

Hassan MO, Duarte R, Dix-Peek T, Dickens C, Naidoo S, Vachiat A, Grinter S, Manga P, Naicker S (2018) Transforming growth factorbeta protects against inflammation-related atherosclerosis in South African CKD patients. Int J Nephrol 2018: 8702372. https://doi. org/10.1155/2018/8702372

Hong-Brown LQ, Brown CR, Navaratnarajah M, Lang CH (2015) Adamts1 mediates ethanol-induced alterations in collagen and elastin via a FoxO1-sestrin3-AMPK signaling cascade in myocytes. I Cell Biochem 116: 91-101. https://doi.org/10.1002/jcb.24945

Ikeda Y, Suehiro T, Yamanaka S, Kumon Y, Takata H, Inada S, Ogami N, Osaki F, Inoue M, Arii K, Hashimoto K (2006) Association between serum ferritin and circulating oxidized low-density lipoprotein levels in patients with type 2 diabetes. Endocr J 53: 665-670. https://doi.org/10.1507/endocrj.k06-010

Jaksch-Bogensperger H, Spiegl-Kreinecker S, Arosio P, Eckl P, Golaszewski S, Ebner Y, Al-Schameri R, Strasser P, Weis S, Bresgen N (2020) Ferritin in glioblastoma. Br J Cancer 122: 1441-1444. https:// doi.org/10.1038/s41416-020-0808-8

Kao JK, Wang SC, Ho LW, Huang SW, Lee CH, Lee MS, Yang RC, Shieh JJ (2020) M2-like polarization of THP-1 monocyte-derived macrophages under chronic iron overload. Ann Hematol 99: 431441. https://doi.org/10.1007/s00277-020-03916-8

Kim SE, Kim UJ, Jang MO, Kang SJ, Jang HC, Jung SI, Lee SS, Park $\mathrm{KH}$ (2013) Diagnostic use of serum ferritin levels to differentiate infectious and noninfectious diseases in patients with fever of unknown origin. Dis Markers 34: 211-218. https://doi.org/10.3233/ DMA-130962

Kraml P (2017) The role of iron in the pathogenesis of atherosclerosis. Physiol Res 66: S55-S67. https://doi.org/10.33549/physiolres.933589

Lauffer RB (1991) Iron stores and the international variation in mortality from coronary artery disease. Med Hypotheses 35: 96-102. https:// doi.org/10.1016/0306-9877(91)90030-3

Lee TS, Shiao MS, Pan CC, Chau LY (1999) Iron-deficient diet reduces atherosclerotic lesions in apoE-deficient mice. Circulation 99: 1222-1229. https://doi.org/10.1161/01.cir.99.9.1222

Liu H, Xiong W, Luo Y, Chen H, He Y, Cao Y, Dong S (2019) Adipokine chemerin stimulates progression of atherosclerosis in ApoE(-/) mice. Biomed Res Int 2019: 7157865. https://doi. org/10.1155/2019/7157865

Livak KJ, Schmittgen TD (2001) Analysis of relative gene expression data using real-time quantitative PCR and the 2(-Delta Delta C(T)) Method. Methods 25: 402-408. https://doi.org/10.1006/ meth.2001.1262

Ma H, Lin H, Hu Y, Li X, He W, Jin X, Gao J, Zhao N, Song B, Pan B, Gao X (2015) Serum ferritin levels are associated with carotid atherosclerosis in Chinese postmenopausal women: the Shanghai Changfeng Study. Br J Nutr 114: 1064-1071. https://doi. org/10.1017/S0007114515001944
MacDonald HB (1993) High stored iron levels are associated with excess risk of myocardial infarction in eastern Finnish men. Circulation 87: 2063-2064. https://doi.org/10.1161/01.cir.87.6.2063

Moore KJ, Sheedy FJ, Fisher EA (2013) Macrophages in atherosclerosis: a dynamic balance. Nat Rev Immunol 13: 709-721. https://doi. org/10.1038/nri3520

Moss JWE, Williams JO, Ramji DP (2018) Nutraceuticals as therapeutic agents for atherosclerosis. Biochim Biophys Acta Mol Basis Dis 1864: 1562-1572. https://doi.org/10.1016/j.bbadis.2018.02.006

Muhoberac BB, Vidal R (2019) Iron, ferritin, hereditary ferritinopathy, and neurodegeneration. Front Neurosici 13: 1195. https://doi. org/10.3389/fnins.2019.01195

Newby AC (2016) Metalloproteinase production from macrophages - a perfect storm leading to atherosclerotic plaque rupture and myocardial infarction. Exp Physiol 101: 1327-1337. https://doi. org/10.1113/EP085567

Pang JH, Jiang MJ, Chen YL, Wang FW, Wang DL, Chu SH, Chau LY (1996) Increased ferritin gene expression in atherosclerotic lesions. $J$ Clin Invest 97: 2204-2212. https://doi.org/10.1172/JCI118661

Rahman K, Vengrenyuk Y, Ramsey SA, Vila NR, Girgis NM, Liu J, Gusarova V, Gromada J, Weinstock A, Moore KJ, Loke P, Fisher EA (2017) Inflammatory Ly6Chi monocytes and their conversion to M2 macrophages drive atherosclerosis regression. J Clin Invest 127: 2904-2915. https://doi.org/10.1172/JCI75005

Rogers JT, Andriotakis JL, Lacroix L, Durmowicz GP, Kasschau KD, Bridges KR (1994) Translational enhancement of H-ferritin mRNA by interleukin- 1 beta acts through 5 ' leader sequences distinct from the iron responsive element. Nucleic Acids Res 22: 2678-2686. https://doi.org/10.1093/nar/22.13.2678

Ruytinx P, Proost P, van Damme J, Struyf S (2018) Chemokine-induced macrophage polarization in inflammatory conditions. Front Immunol 9: 1930. https://doi.org/10.3389/fimmu.2018.01930

Soeki T, Sata M (2016) Inflammatory biomarkers and atherosclerosis. Int Heart J 57: 134-139. https://doi.org/10.1536/ihj.15-346

Taleb S (2016) Inflammation in atherosclerosis. Arch Cardiovasc Dis 109: 708-715. https://doi.org/10.1016/j.acvd.2016.04.002

Tran TN, Eubanks SK, Schaffer KJ, Zhou CY, Linder MC (1997) Secretion of ferritin by rat hepatoma cells and its regulation by inflammatory cytokines and iron. Blood 90: 4979-4986

Tuomainen TP, Diczfalusy U, Kaikkonen J, Nyyssonen K, Salonen JT (2003) Serum ferritin concentration is associated with plasma levels of cholesterol oxidation products in man. Free Radic Biol Med 35: 922-928. https://doi.org/10.1016/s0891-5849(03)00433-7

Vlad M, Caseanu E, Uza G, Petrescu M (1994) Concentration of copper, zinc, chromium, iron and nickel in the abdominal aorta of patients deceased with coronary heart disease. I Trace Elem Electrolytes Health Dis 8: 111-114

Wan Q, Liu Z, Yang Y, Cui X (2018) Suppressive effects of berberine on atherosclerosis via downregulating visfatin expression and attenuating visfatin-induced endothelial dysfunction. Int J Mol Med 41: 1939-1948. https://doi.org/10.3892/ijmm.2018.3440

Wang YN, Wang Q, Wang C, Zhao W (2017) Effect of recombinant antigen ferritin on dc induce immune response. Sichuan Da Xue Xue Bao Yi Xue Ban 48: 834-839 (in Chinese)

Wolff B, Volzke H, Ludemann J, Robinson D, Vogelgesang D, Staudt A, Kessler C, Dahm JB, John U, Felix SB (2004) Association between high serum ferritin levels and carotid atherosclerosis in the study of health in Pomerania (SHIP). Stroke 35: 453-457. https:// doi.org/10.1161/01.STR.0000114875.31599.1C

Xu H, Song Y, Xu J, Gu Y, Zhang Q, Liu L, Meng G, Wu H, Xia Y, Bao X, Shi H, Su Q, Fang L, Yu F, Yang H, Sun S, Wang X, Zhou M, Jia Q, Wang G, Song K, Wu Y, Sun Z, Niu K (2017) Increased serum ferritin levels are independently associated with carotid atherosclerosis in women. Br J Nutr 117: 1623-1630. https:// doi.org/10.1017/S0007114517001544

Zhang J, Zu Y, Dhanasekara CS, Li J, Wu D, Fan Z, Wang S (2017) Detection and treatment of atherosclerosis using nanoparticles. Wiley Interdiscip Rev Nanomed Nanobiotechnol 9: https://doi.org/10.1002/ wnan. 1412

Zhu S, Xu G, Fui G, Li M (2006) Levels of serum ferritin associated with the severity and prognosis of coronary atherosclerosis. Zhejiang Prev Med 18: 8-12. https://doi.org/10.19485/j.cnki.issn10070931.2006 .01 .004 